\title{
Takashi Hayashi awarded the 2019 Japanese Economic Association Nakahara Prize
}

\author{
Sagiri Kitao ${ }^{1}$
}

Published online: 9 December 2019

(C) Japanese Economic Association 2020

The Japanese Economic Association (JEA) Nakahara Prize was established in 1995 and has been funded by a donation from Mr. Nobuyuki Nakahara. The prize was established to honour researchers in economics under the age of 45 who have made significant contributions that are internationally recognized.

It is a great pleasure to announce that the 2019 JEA Nakahara Prize has been awarded to Professor Takashi Hayashi. Born in 1974, Professor Hayashi received a Master's degree in economics from Osaka University in 1998, and earned a Ph.D. in economics from University of Rochester in 2004. He is currently Professor in Economics at Adam Smith Business School, University of Glasgow.

Professor Hayashi has made a range of important contributions to a variety of fundamental issues in economic theory. Among them, two lines of research are best recognized internationally. First, Gajdos et al. (2008) is widely regarded as one of the key contributions in the decision theory. The paper presents an axiomatic model of decision making, where a decision maker's attitude towards precision (or ambiguity) of information has a clean representation. The innovation of their research is to consider a situation where a decision maker can choose the precision of information about the underlying state. This broke a new ground in the literature on ambiguity aversion initiated by the Ellsberg paradox.

Secondly, Chambers and Hayashi (2014) provide a sweeping and fundamental characterization of social choice under asymmetric information. It considers a reasonably weak criterion of "Common Pareto", which states that social preference prefers a particular act to another, if it is common knowledge among asymmetrically informed agents that such an act Pareto dominates the other. The paper shows that Common Pareto, together with regularity conditions, implies a surprisingly strong and natural property: the existence of a common prior probability of underlying state and that the social preference is represented by a weighted sum of agents' expected utilities with respect to the common prior. The research contributed to development of theoretical foundations in information economics.

Sagiri Kitao

skitao@e.u-tokyo.ac.jp

1 The University of Tokyo, Tokyo, Japan 
These significant contributions that Professor Hayashi made to economic theory led the selection committee to decide to award him the 2019 Nakahara Prize.

Selection committee

Sagiri Kitao, The University of Tokyo (Chair-person)

Anton Braun, Federal Reserve Bank of Atlanta

Federico Echenique, California Institute of Technology

Fumio Hayashi, National Graduate Institute for Policy Studies

Hideshi Itoh, Waseda University

Michihiro Kandori, The University of Tokyo

Yuichi Kitamura, Yale University

\section{References}

Chambers, C. P., \& Hayashi, T. (2014). Preference aggregation with incomplete information. Econometrica, 82(2), 589-599.

Gajdos, T., Hayashi, T., Tallon, J. M., \& Vergnaud, J. C. (2008). Attitude toward imprecise information. Journal of Economic Theory, 140(1), 27-65.

Publisher's Note Springer Nature remains neutral with regard to jurisdictional claims in published maps and institutional affiliations. 